\title{
Factors Associated with Psychological Distress and Brief Resilient Coping Level During the COVID-19 Pandemic Among Health-Care Professionals in Dessie, Ethiopia
}

This article was published in the following Dove Press journal:

Psychology Research and Behavior Management

\section{Mekonnen Tsehay (DD \\ Asmare Belete $\mathbb{D}$ \\ Mogesie Necho}

Wollo University, College of Medicine and Health Science, Department of Psychiatry, South Wollo, Dessie, Ethiopia
Correspondence: Mekonnen Tsehay Lecturer of Psychiatry, Wollo University, Po. Box: I I45, South Wollo, Dessie, Ethiopia

Tel +251912991308

Email jimma1760@gmail.com
Background: The outbreak of Coronavirus Disease 2019 (COVID-19) has caused serious threats to people's health and lives in the world. The health-care professionals are bravely fighting on the front lines of the pandemic everywhere in the world. Our study is the first to study psychological distress and coping status among health-care professionals of Dessie town, Ethiopia during the unbridled time of the COVID-19 outbreak.

Methods: A cross-sectional internet-based study was conducted between June 20 and July 13, 2020. The questionnaires included the demographic information, COVID-19 related questions, Kasseler-10 to assess psychological distress level and Brief Resilient Coping Scale, and Oslo-3 social support scale questionnaire were employed.

Results: A total of 423 participants were involved in the study with a response rate of $100 \%$. The mean age of respondents was 34.5 years $(\mathrm{SD}= \pm 8.45$ years). The prevalence of psychological distress among participants was $42 \%$. Of these $18 \%, 11 \%$, and $13 \%$ had mild, moderate, and severe psychological distress levels. Being married, being nurses and pharmacies, current substance users, working in emergency and outpatient departments, history of chronic medical illness, brief resilient coping level, and social support level were particularly associated with high psychological distress.

Conclusion: Health-care professionals are experiencing a substantial level of psychological distress. In addition to other modifying factors coping level and social support was a significant predictor of psychological distress among health-care professionals. These findings should inform the implementation of interventions that increase coping resilience and social support to mitigate the impact of psychological distress among health-care professionals.

Keywords: COVID-19, health care professionals, psychological distress, coping, social support

\section{Introduction}

Coronavirus disease 2019 (COVID-19) is a global pandemic caused by Severe Acute Respiratory Syndrome Coronavirus-2. ${ }^{1}$ Consequently, in the world hospitals and other health-care services have had to rapidly reconfigure clinical spaces and restructure clinical teams for the surge of patients with COVID-19.

Many health-care workers have therefore been reassigned to areas outside their usual clinical specialty/expertise, often working extra shifts and longer hours to meet high volume patient demand. As Coronavirus disease 2019 (COVID-19) is 
highly infectious, health-care workers suffer from psychological distress because of increased risk of acquiring and potentially transmitting COVID-19 to patients, coworkers, and family members. ${ }^{2,3}$

Psychological distress refers to the presence of a nonspecific negative mental health state composed of multidimensional constructs, such as depression and anxiety. ${ }^{4,5}$ In general term, it is also considered as the result of factors (psychogenic pain, internal conflicts, and external stress) that impair the proper functioning of the individual's daily life but Symptoms of anxiety and depression in persons do not fit the established criteria of psychological distress. ${ }^{6}$ However, the condition is a warning flag of a clinical major depressive event for those vulnerable to such events. ${ }^{7,8}$

Psychological distress is a maladaptive response to a stressful situation. It occurs when external events or stressors place demands upon us that we are unable to cope with; As a result, we start to show symptoms of psychological distress. ${ }^{9}$

In previous disease outbreaks, A/H1N1 influenza, and severe acute respiratory syndrome (SARS), many people including health-care workers (HCWs) presented with high levels of psychological distress (18-57\%), because of concerns regarding their health and families' health, worries about functional ability and fears of stigmatization. $^{10-14}$

Current research during the pandemic of Coronavirus (COVID-19), psychological distress among health-care workers is common in developed countries and is a major public health challenge. ${ }^{2,15,16}$ In Chinese healthcare workers found that $>70 \%$ reported distress during the COVID-19 pandemic, ${ }^{17}$ in New York health-care workers reported $57 \%$ acute stress, $48 \%$ depressive, and $33 \%$ anxiety symptoms, ${ }^{2}$ and In Singapore, $14.5 \%$ of participants screened positive for anxiety, $8.9 \%$ for depression, $6.6 \%$ for stress, and $7.7 \%$ for clinical concern of PTSD. ${ }^{15}$

Furthermore, in a systematic review and meta-analysis done in April 2020, the Prevalence of depression, anxiety, and insomnia among health-care workers during the COVID-19 pandemic were $22.8 \%, 23.2 \%$, and $38.9 \%$ for depression, anxiety, and insomnia, respectively. ${ }^{18}$

Since March 13, 2020, The Federal Ministry of Health has confirmed a coronavirus disease (COVID-19) case in Addis Ababa, Ethiopia, currently, the number of infected reach one hundred thousand. And still, now quantitative data about the COVID-19-related psychological distress, coping and associated factors among Ethiopian health-care workers are lacking. This study reports the prevalence of COVID-19-related psychological distress that health-care workers are experiencing, their current coping behaviors, and factors associated with psychological distress among health-care professionals in Dessie referral hospital, Ethiopia.

\section{Methods}

\section{Study Design, Study Area, Period, and Population}

The internet-based cross-sectional study was conducted from June 20-July13, 2020 at Dessie town, south Wollo zone, Western Amhara region, Ethiopia. Dessie is a multiethnic city in Northeastern Ethiopia located $401 \mathrm{Km}$ away from Addis Ababa, the capital city of Ethiopia. There are two public and three private hospitals, seven public health centers, and more than 24 private clinics. All health professionals working in Governmental Health Institutions of Dessie town were considered as the study populations.

\section{Inclusion Criteria}

Government employee health professionals who were on duty during the pandemic of COVID-19 and have access to the internet to use Facebook, email, and telegram were included.

\section{Exclusion Criteria}

Lack of access to the internet and the inability to complete the online survey were excluded.

\section{Sample Size Determination}

The sample size was calculated using a single population proportion formula with an assumption of $95 \%$ confidence level, marginal of error $5 \%$, and $50 \%$ proportion.

In which $\mathrm{n}=[(1.96) 2(0.5)(1-0.5)] /(0.05) 2=385$ adding $10 \%$ non-response rate; $\mathrm{n}=423$.

\section{Sampling Procedure and Data Collection}

The questionnaire was created through Google Form and the survey link was shared by e-mail, Telegram, and Facebook, to assess psychological distress during COVID - 19 pandemic. In the online questionnaire, participants were asked to give informed consent for participation by ticking the "Yes, I Agree" box, and not the "No thanks," box on the online form. The questionnaire was available online for three weeks, from June 20 to July 13, 2020, still the desired sample size were mate. During the 
study period, we followed the completion of questionnaires, observing the date and time of the study end.

\section{The Questionnaire}

The questionnaire prepared including questions concerning socio-demographic data; age, sex, marital status, ethnicity, religion, number of families, working department, profession/specialty, presence of chronic disease, history of substance use, working hours, monthly income, social support, resilience level, COVID-19 related knowledge and experience, and finally k-10 for assessment of distress were included in Google form.

\section{Tools}

Kessler Psychological Distress Scale (K10) is a measure of psychological distress. The numbers attached to the participants 10 responses are added up to get the total score on the Kessler Psychological Distress Scale (K10). Scores will range from 10 to 50 . The final K10 score was categorized into four levels: People who score under 20 are likely to be well, score 20-24 are likely to have a mild mental disorder, and score 25-29 are likely to have a moderate mental disorder, score 30 and over are likely to have a severe mental disorder. ${ }^{19}$ It is validated in Ethiopia among postnatal mothers with sensitivity, specificity, and misclassification rates of $84.2 \%, 77.8 \%$, and $21.0 \%$ at a cut-off point of $6 / 7$, respectively. ${ }^{18}$

Brief Resilient Coping Scale (BRCS): Vissoci S. and et $\mathrm{al}^{20}$ "The Brief Resilient Coping Scale (BRCS) captures tendencies to cope with stress adaptively. The scale focuses on the tendency to effectively use coping strategies inflexible, committed ways to actively solve problems despite stressful circumstances". Five-point scale response, ranging from $1=$ does not describe me at all to $5=$ describes me very well and Total sum scores range from 4 to 20. Scores of 4-13 indicate low resilient coping, 14-16 indicate medium resilient coping and 17-20 indicate high resilient coping. ${ }^{20}$

Social support was also assessed by the Oslo-3 social support scale, the total SSRS score ranges from 1 to 14 points, with higher scores indicating a higher level of social support. The SSRS has shown good reliability and validity, with Cronbach's $\alpha$ ranging between 0.83 and $0.86 .{ }^{21}$

\section{Data Processing and Analysis}

The collected data were cleaned, coded, and entered into SPSS version 20. Errors related to inconsistency were verified using cross-tabulation and frequency data. To identify predictors of psychological distress, we classified respondents into those with have psychological distress (K10 score $\geq 21)$ and those with no/low psychological distress (K10 score $\leq 20) .{ }^{19}$ To identify factors influencing psychological distress among respondents, we performed binary logistic regression and multiple logistic regressions. The dependent variables were the dichotomous classification of no/low or have psychological distress. The model was constructed with the following covariates: sociodemographic variables, COVID-19 related knowledge and experience, social support, and history of ever and current substance use.

\section{Results}

\section{Socio-Demographic Characteristics of Respondents}

A total of 423 participants were involved in the study with a response rate of $100 \%$. The mean age of respondents was 34.5 years $(\mathrm{SD}= \pm 8.45$ years). More than half $232(56.2 \%)$ of the respondents were females. A majority, 345 (83.5\%) and 262 (63.4\%) were Amhara by ethnicity and married in marital status, respectively. The majority of respondents were BSC holders 292 (70.7\%) and the Brief resilient coping score shows that $301(72.9 \%)$ were low resilient, 98 (23.7\%) moderate and 14 (3.4\%) high resilient level of coping (Table 1). And in terms of social support, 132 (32\%), of the participants have low social support levels, $152(36.8 \%)$ and $129(31.2 \%)$ have moderate and high social support levels, respectively.

\section{Prevalence and Severity of Psychological Distress}

Figure 1 shows the percentage of participants who rated more than 20 in Kessler-10 as having psychological distress were $42 \%$ (95\% CI, 37\%-46.5\%). $85.5 \%$ of participants reported that concerns about transmitting COVID-19 to family and loved ones were the highly psychological distressing reason they faced.

The majority of participants rated the Emotional strain/ physical exhaustion, shortages of personal protective equipment, concerns about infecting family members, shortages of ventilators and other crucial medical equipment, fear of limited access to childcare during increased work hours, and Fear of being able to provide competent medical care if deployed to a new area are as highly distressing reasons they faced (Figure 2). 
Table I Socio-Demographic Characteristics of Health-care professionals in Dessie town, Dessie, Ethiopia, 2020 ( $N=423)$

\begin{tabular}{|c|c|c|c|}
\hline Variables & $\begin{array}{l}\text { Sub- } \\
\text { Category }\end{array}$ & Frequency & $\begin{array}{l}\text { Percentage } \\
\text { (\%) }\end{array}$ \\
\hline $\begin{array}{l}\text { Age of the } \\
\text { respondent }\end{array}$ & $\begin{array}{l}<=29 \\
30-37 \\
38+\end{array}$ & $\begin{array}{l}14 \mid \\
14 \mid \\
131\end{array}$ & $\begin{array}{l}34.1 \\
34.1 \\
31.7\end{array}$ \\
\hline Gender & $\begin{array}{l}\text { Male } \\
\text { Female }\end{array}$ & $\begin{array}{l}181 \\
232\end{array}$ & $\begin{array}{l}43.8 \\
56.2\end{array}$ \\
\hline Marital status & $\begin{array}{l}\text { Married } \\
\text { Single } \\
\text { Divorce and } \\
\text { widowed } \\
\text { Separated }\end{array}$ & $\begin{array}{l}262 \\
108 \\
17 \\
26\end{array}$ & $\begin{array}{l}63.4 \\
26.2 \\
4.1 \\
\\
6.3\end{array}$ \\
\hline Ethnicity & $\begin{array}{l}\text { Amhara } \\
\text { Oromo } \\
\text { Tigry } \\
\text { Other }\end{array}$ & $\begin{array}{l}345 \\
35 \\
22 \\
11\end{array}$ & $\begin{array}{l}83.5 \\
8.5 \\
5.3 \\
2.7\end{array}$ \\
\hline Religion & $\begin{array}{l}\text { Orthodox } \\
\text { Muslim } \\
\text { Protestant } \\
\text { Catholic }\end{array}$ & $\begin{array}{l}250 \\
140 \\
21 \\
2\end{array}$ & $\begin{array}{l}60.5 \\
33.9 \\
5.1 \\
0.5\end{array}$ \\
\hline Educational level & $\begin{array}{l}\text { College } \\
\text { diploma } \\
\text { BSc } \\
\text { MSc } \\
\text { GP }\end{array}$ & $\begin{array}{l}89 \\
292 \\
21 \\
11\end{array}$ & $\begin{array}{l}21.5 \\
\\
70.7 \\
5.1 \\
2.7\end{array}$ \\
\hline Salary in birr & $\begin{array}{l}<4000 \\
4000-5044 \\
5044.5-6199 \\
6000-7999 \\
>800\end{array}$ & $\begin{array}{l}41 \\
62 \\
122 \\
42 \\
146\end{array}$ & $\begin{array}{l}9.9 \\
15 \\
29.5 \\
10.2 \\
35.4\end{array}$ \\
\hline $\begin{array}{l}\text { Number of family } \\
\text { members }\end{array}$ & $\begin{array}{l}6 \text { and above } \\
\text { Three-five } \\
\text { Two and } \\
\text { one }\end{array}$ & $\begin{array}{l}45 \\
246 \\
122\end{array}$ & $\begin{array}{l}10.5 \\
59.6 \\
29.5\end{array}$ \\
\hline Level of resilience & $\begin{array}{l}\text { low } \\
\text { resilience } \\
\text { medium } \\
\text { resilience } \\
\text { high } \\
\text { resilience }\end{array}$ & $\begin{array}{l}301 \\
98 \\
14\end{array}$ & $\begin{array}{l}72.9 \\
23.7 \\
3.4\end{array}$ \\
\hline Social support & $\begin{array}{l}\text { low social } \\
\text { moderate } \\
\text { Strong }\end{array}$ & $\begin{array}{l}132 \\
152 \\
129\end{array}$ & $\begin{array}{l}32.0 \\
36.8 \\
31.2\end{array}$ \\
\hline $\begin{array}{l}\text { History of chronic } \\
\text { illness }\end{array}$ & Yes & 59 & 26.5 \\
\hline
\end{tabular}

(Continued)
Table I (Continued)

\begin{tabular}{|l|l|l|l|}
\hline Variables & $\begin{array}{l}\text { Sub- } \\
\text { Category }\end{array}$ & Frequency & $\begin{array}{l}\text { Percentage } \\
\text { (\%) }\end{array}$ \\
\hline & No & 354 & 73.5 \\
\hline $\begin{array}{l}\text { How many hours did } \\
\text { you work /week }\end{array}$ & $<58$ hours & 332 & 80.4 \\
\hline Health institution & $\begin{array}{l}\text { DRH hours } \\
\text { Health } \\
\text { centers }\end{array}$ & 81 & 19.6 \\
\hline Working department & $\begin{array}{l}\text { Internal } \\
\text { medicine } \\
\text { Emergency } \\
\text { Surgery } \\
\text { Pediatric } \\
\text { Outpatient } \\
\text { Gyn/obs }\end{array}$ & $\begin{array}{l}59 \\
119\end{array}$ & $\begin{array}{l}70 \\
83\end{array}$ \\
\hline
\end{tabular}

Abbreviations: N:B; DRH, Dessie Referral Hospital; Gyn/obs, gynecology and obstetrics; Other, Gurage, Debube; BSc, bachelors of science; MSc, masters of science.

As shown in Figure 3 all respondents have excellent knowledge about COVID-19 regarding; ways of transmission covid-19, as covid-19 is airborne, they know that covid-19 is worldwide/pandemic, and they have information that the current number of infected and death was increasing in the world as well in Ethiopia.

\section{Factors Associated with Psychological} Distress Among Health Care Professional The multivariate logistic regression analysis showed that being married ( $\mathrm{AOR}=2.062,95 \% \mathrm{CI}: 1.473,4.412)$, being Nurse $(A O R=4.678,95 \%$ CI: 1.241, 17.633), being Pharmacy $(\mathrm{AOR}=4.549,95 \%$ CI: $1.239,16.704)$, current

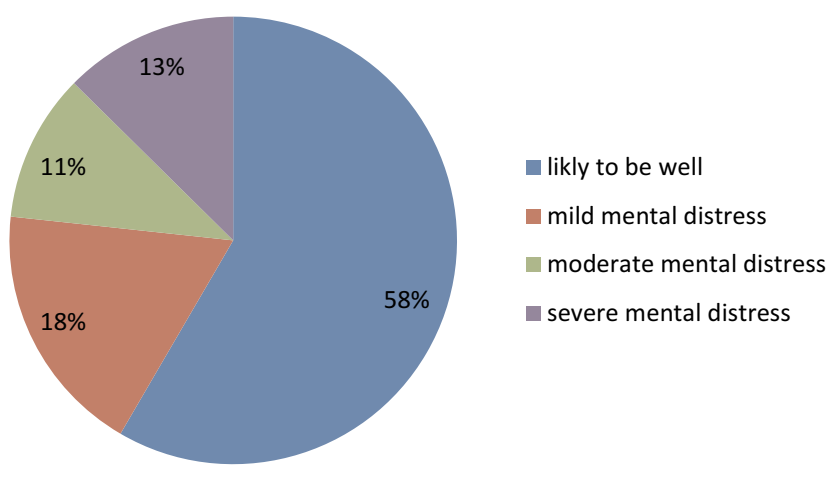

Figure I Prevalence and severity of psychological distress among respondents. 


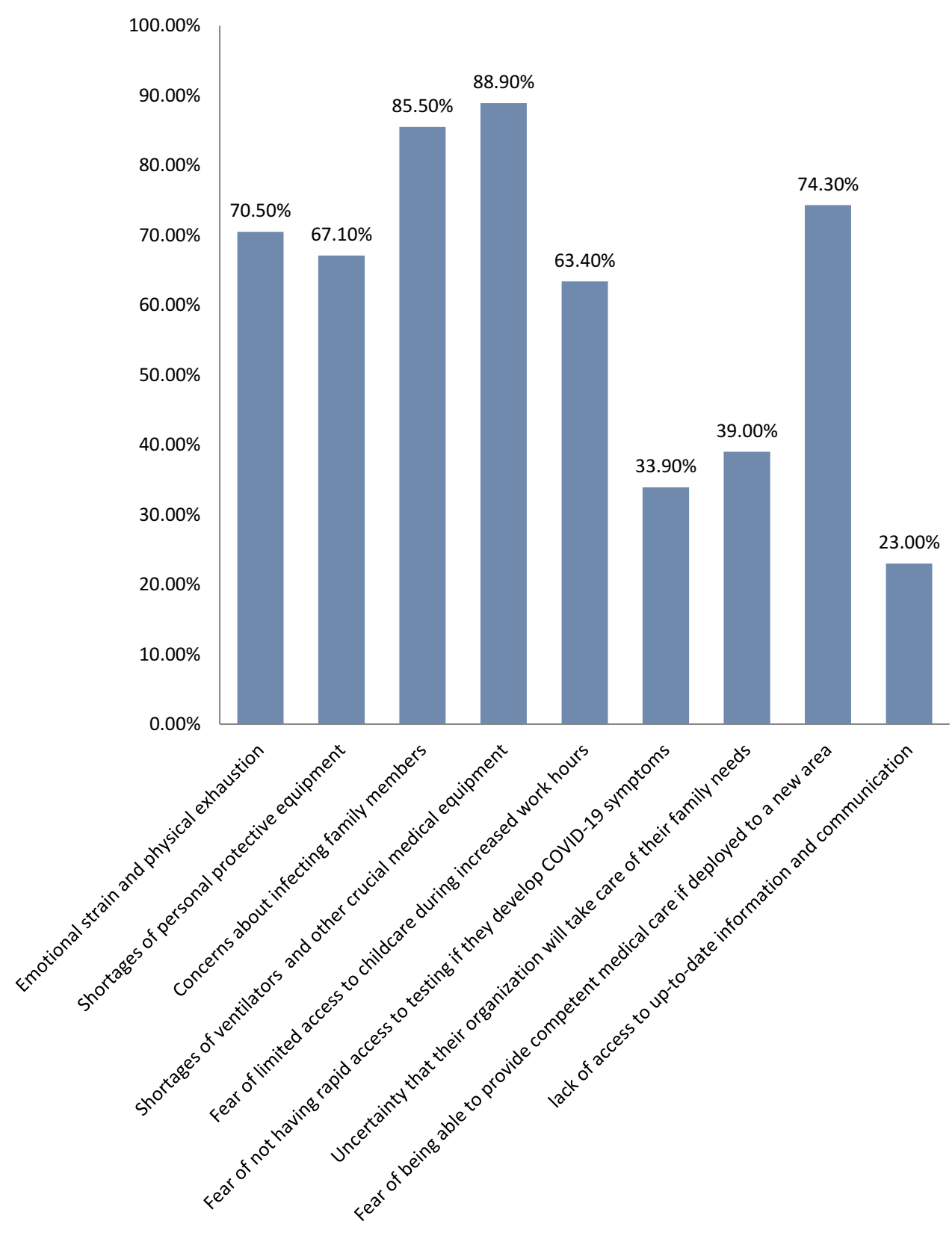

Figure 2 Possible reasons that lead respondents to psychological distress during the pandemic of COVID-19.

substance user $(\mathrm{AOR}=2.786,95 \% \mathrm{CI}: 1.912,9.015)$, working in emergency department $(\mathrm{AOR}=2.360,95 \% \mathrm{CI}: 1.108$, 7.730), working in outpatient department (AOR $=1.470$, 95\% CI: 1.040, 3.740), having history of chronic medical illness $(\mathrm{AOR}=1.670,95 \% \mathrm{CI}: 1.101,3.740)$, having low level brief resilient coping $(\mathrm{AOR}=5.023,95 \% \mathrm{CI}: 2.963$, $10.120)$, having medium level brief resilient coping ( $\mathrm{AOR}=$ 2.023, 95\% CI: 1.002, 4.025), low social support level (AOR $=1.875,95 \% \mathrm{CI}: 1.025,3.542)$ and medium social support level $(\mathrm{AOR}=0.845,95 \% \mathrm{CI}: 0.356,0.958)$ were found significantly linked with psychological distress among health professionals in Dessie town (Table 2).

\section{Discussion}

The current cross-sectional study of levels of psychological distress in health-care workers on duty during the pandemic of COVID-19 in Dessie town is, to our knowledge, the first study in Ethiopia. Almost 42\% (95\% CI, $37 \%-46.5 \%$ ) of health-care workers screened positive for psychological distress; of these $18 \%, 11 \%$, and $13 \%$ were 


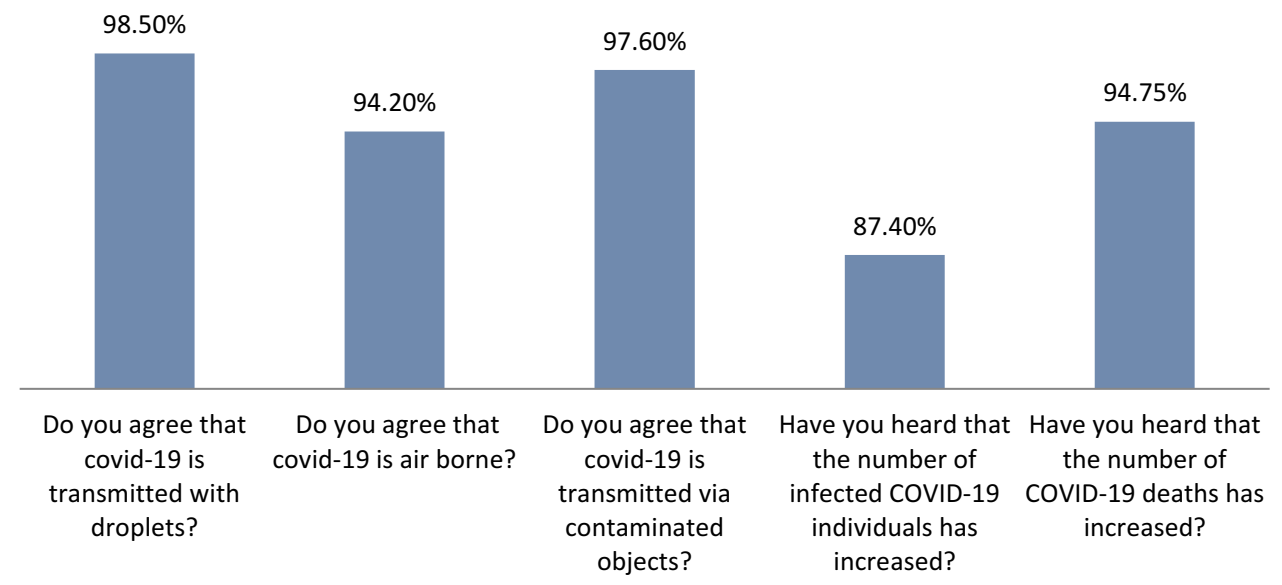

Figure 3 Assessment of knowledge of health care professionals regarding covid-19 pandemic.

mild, moderate, and severe level psychological distress according to Kessler 10 rating scale. According to the scale, those who score moderate and severe level are at high risk for psychological distress (depression and anxiety) need further formal assessment diagnostic evaluation, and treatment. ${ }^{22}$

The prevalence of psychological distress among healthcare professionals in this study in line with a study done in china to assess the psychological health status of frontline health-care professionals during the 2019 novel coronavirus using the Perceived Stress Scale (PSS-10). ${ }^{23}$

But the prevalence of psychological distress among health-care professionals in this study was lower than the study was done in Spain, which were $80.6 \%$ among frontline health-care workers ${ }^{24}$ and China among health-care workers exposed to COVID-19 reported as $70 \% .{ }^{17}$ The difference might be due to the screening tool used (general health questionnaire), high mortality report in Spain than Ethiopia, and study population difference.

And also the prevalence of psychological distress among health-care professionals in this study was higher than the study done in china only on frontline Nurse Professional which shows $25 \%$ of nurses had psychological distress according to GHQ they used which might be responsible for the difference in addition to the study population difference. $^{25}$

In line with previous research, the majority of participants in this study were highly distressed by COVID-19 related Emotional strain/physical exhaustion, shortages of personal protective equipment, concerns about infecting family members, shortages of ventilators and other crucial medical equipment, fear of limited access to childcare during increased work hours, and Fear of being able to provide competent medical care if deployed to a new area. ${ }^{17,26,27}$

Although all health-care workers on duty during the pandemic of COVID-19 are expected to experiencing distress, being married, being nurses and pharmacies, current substance users, working in emergency and outpatient departments, history of chronic medical illness, brief resilient coping level and social support level were particularly associated with high psychological distress.

Consistent with another finding, ${ }^{28,29}$ From sociodemographic variables those who had married have higher odds than non-married (single, divorced, widowed, and separated). This might be due to the fear of infecting family members.

The other finding of the current study was significant associations of being nurse and pharmacies as compared to the midwife, physicians, and psychiatric nurse working outpatient only. The different responsibilities of nurses and pharmacies may explain the higher odds of positive psychological distress, as they are spending more time delivering direct patient care in place of patients' families who are not allowed inside the hospital due to transmission concerns during the pandemic.

Current finding in line with other finding shows significant association with current substance users and history of one or more chronic medical illness. These might be related that it is frequently reported as a use of the substance and having chronic medical illness during the pandemic increases morbidity and mortality. ${ }^{30-34}$

Indeed, our findings show that brief resilient coping levels were associated with lower psychological distress; especially those who score medium and high level of brief resilient coping level have a significant negative 
Table 2 Bivariate and multivariate model of health-care professional working at Dessie town health institutions, 2020

\begin{tabular}{|c|c|c|c|c|c|}
\hline Variables & Choice & COR and $95 \% \mathrm{Cl}$ & P-value & AOR and $95 \% \mathrm{Cl}$ & p-value \\
\hline Age of respondent & $\begin{array}{l}\leq 29 \\
30-37 \\
38+\end{array}$ & $\begin{array}{l}0.062(0.47 I-0.4 I 0) \\
0.60 I(0.250-I .440)\end{array}$ & $\begin{array}{l}0.042 \\
0.021\end{array}$ & $\begin{array}{l}0.454(0.206-1.002) \\
0.685(0.369-1.27 I) \\
\text { Ref. }\end{array}$ & $\begin{array}{l}0.051 \\
0.231\end{array}$ \\
\hline Marital status & $\begin{array}{l}\text { Married } \\
\text { Not married* }\end{array}$ & $1.264(0.82-1.95)$ & 0.032 & $\begin{array}{l}2.062(I .473-4.4 \mid 2) \\
\text { Ref. }\end{array}$ & 0.001 \\
\hline Type of profession & $\begin{array}{l}\text { Nurse } \\
\text { laboratory } \\
\text { pharmacy } \\
\text { Public health officer } \\
\text { Others** }\end{array}$ & $\begin{array}{l}6.007(2.001-9.051) \\
3.042(1.005-5.317) \\
2.075(I .01-4.59) \\
3.012(2.001-5.311)\end{array}$ & $\begin{array}{l}0.001 \\
0.002 \\
0.014 \\
0.001\end{array}$ & $\begin{array}{l}4.678(1.24 I-17.633) \\
3.156(0.757-13.164) \\
4.549(1.239-16.704) \\
4.00 I(0.926-17.28 I) \\
\text { Ref. }\end{array}$ & $\begin{array}{l}0.023 \\
0.115 \\
0.022 \\
0.063\end{array}$ \\
\hline Current substance use & $\begin{array}{l}\text { Yes } \\
\text { No }\end{array}$ & $5.36(1.18-24.35)$ & 0.001 & $\begin{array}{l}2.786(1.912-9.015) \\
\text { Ref. }\end{array}$ & 0.030 \\
\hline Working department & $\begin{array}{l}\text { Emergency } \\
\text { Surgery } \\
\text { Pediatric } \\
\text { Outpatient } \\
\text { Gyn/obs } \\
\text { Internal medicine }\end{array}$ & $\begin{array}{l}3.021(1.320-6.20 I) \\
0.890(0.560-1.410) \\
I .132(0.760-1.670) \\
I .612(1.012-2.570) \\
0.34 I(0.190-0.760)\end{array}$ & $\begin{array}{l}0.001 \\
0.213 \\
0.412 \\
0.040 \\
0.002\end{array}$ & $\begin{array}{l}2.360(1.108-7.730) \\
0.390(0.180-1.880) \\
1.150(0.050-3.440) \\
1.420(1.040-3.740) \\
0.619(0.309-1.280) \\
\text { Ref. }\end{array}$ & $\begin{array}{l}0.003 \\
0.105 \\
0.124 \\
0.001 \\
0.245\end{array}$ \\
\hline having chronic medical or mental illness & $\begin{array}{l}\text { Yes } \\
\text { No }\end{array}$ & $9.74(2.306-15.325)$ & 0.001 & $\begin{array}{l}\text { I.670(I.10I-3.500) } \\
\text { Ref. }\end{array}$ & 0.002 \\
\hline Health institutions & $\begin{array}{l}\text { referral hospital } \\
\text { Health center }\end{array}$ & $0.689(0.206-0.992)$ & 0.025 & $\begin{array}{l}0.377(0.13|-| .08 I) \\
\text { Ref. }\end{array}$ & 0.107 \\
\hline Brief resilient coping level & $\begin{array}{l}\text { Low resilient } \\
\text { Medium resilient } \\
\text { High resilient }\end{array}$ & $\begin{array}{l}\text { II.50I(5.940-22.2I7) } \\
2.589(1.649-4.065)\end{array}$ & $\begin{array}{l}0.001 \\
0.001\end{array}$ & $\begin{array}{l}5.023(2.963-10.120) \\
2.023(1.002-4.025) \\
\text { Ref. }\end{array}$ & $\begin{array}{l}0.012 \\
0.045\end{array}$ \\
\hline Social support & $\begin{array}{l}\text { low social } \\
\text { moderate } \\
\text { Strong }\end{array}$ & $\begin{array}{l}2.08(1.636-6.707) \\
0.730(0.453-0.984)\end{array}$ & $\begin{array}{l}0.020 \\
0.120\end{array}$ & $\begin{array}{l}\text { I.875(I.025-3.542) } \\
0.845(0.356-0.958) \\
\text { Ref. }\end{array}$ & $\begin{array}{l}0.004 \\
0.017\end{array}$ \\
\hline
\end{tabular}

Notes: NB: others**= midwife, physicians and psychiatric nurse; others*= not married=single, divorced, widowed and separated.

association with the odds of psychological distress. This finding was in line with other previous finding done in Switzerland, which was a longitudinal cohort study among young adults during the COVID-19 pandemic. $^{35}$ This shows coping strategies should be used by health-care professionals in facing the highly stressful situation caused by the COVID-19 pandemic.

In our study in terms of social support, almost onefourth (32\%), of the participants have low social support level. Which we found is risk factor for psychological distress and also it is consistent with other findings. ${ }^{36,37}$

The findings of this study have the following limitations. First, it is only generalizable for situations of the current COVID-19 pandemic, and using cross-sectional design excluded the evaluation of the effects of participant's characteristics on distress levels. Second, since we used online methods the sample was not randomized and this may have affected our results. The third, power of our findings may have been reduced by using questionnaire-based assessment than the clinical interview. Despite these limitations, we are confident the findings of this study reflect the possible psychological distress among health-care professionals during the pandemic of COVID-19.

\section{Conclusions}

We studied health-care professionals on duty during the pandemic COVID-19 in Dessie, one of the towns of Amhara regions, which have the highest level of infection record of COVID-19. We quantified several sources of distress, ranging 
from fears of COVID-19-related variables, psychological distress level, coping levels, and social support levels.

The health-care professionals are experiencing a substantial level of psychological distress. In addition to other modifying factors coping levels and social support was a significant predictor of psychological distress among health-care professionals. Coping resilience is important in adapting to and struggling against challenging life events. According to our study, Increased coping resilience is associated with reduced symptoms of psychological distress.

These findings should inform the implementation of interventions that increase coping resilience and social support to mitigate the impact of psychological distress among health-care professionals.

\section{Data Sharing Statement}

The datasets used and analyzed during the current study are available from the corresponding author on reasonable request.

\section{Ethics Approval and Consent to Participate}

The research was approved by the Institutional Review Board (IRB) from Wollo University College of medicine and health science before data collection. This study was conducted in accordance with the Declaration of Helsinki.

\section{Acknowledgments}

We would like to thank Wollo University, Dessie town health-care professionals as study participants' cooperation for data collection.

\section{Author Contributions}

All authors made substantial contributions to conception and design, acquisition of data, or analysis and interpretation of data; took part in drafting the article or revising it critically for important intellectual content; agreed to submit to the current journal; gave final approval of the version to be published; and agree to be accountable for all aspects of the work.

\section{Funding}

This research was supported by Wollo University. The funder has no role in the interpretation of findings and decisions for publication.

\section{Disclosure}

The authors declare that they have no conflicts of interest in this work.

\section{References}

1. Andersen KG, Rambaut A, Lipkin WI, Holmes EC, Garry RF. The proximal origin of SARS-CoV-2. Nat Med. 2020;26(4):450-452. doi:10.1038/s41591-020-0820-9

2. Shechter A, Diaz F, Moise N, et al. Psychological distress, coping behaviors, and preferences for support among New York healthcare workers during the COVID-19 pandemic. Gen Hosp Psychiatry. 2020;66:1-8. doi:10.1016/j.genhosppsych.2020.06.007

3. Qiu J, Shen B, Zhao M, Wang Z, Xie B, Xu Y. A nationwide survey of psychological distress among Chinese people in the COVID-19 epidemic: implications and policy recommendations. General Psychiatry. 2020;33(2):2. doi:10.1136/gpsych-2020-100213

4. Brooks RT, Beard J, Steel Z. Factor structure and interpretation of the K10. Psychol Assess. 2006;18(1):62. doi:10.1037/1040-3590.18.1.62

5. Sadock BJ, Sadock VA. Kaplan and Sadock's Synopsis of Psychiatry: Behavioral Sciences/Clinical Psychiatry. Lippincott Williams \& Wilkins; 2011.

6. Ridner SH. Psychological distress: concept analysis. $J$ Adv Nurs. 2004;45(5):536-545. doi:10.1046/j.1365-2648.2003.02938.x

7. Emmanuel E, St John W. Maternal distress: a concept analysis. $J A d v$ Nurs. 2010;66(9):2104-2115.

8. Armstrong TS, editor. Symptoms Experience: A Concept Analysis. Oncology Nursing Forum. ONCOLOGY NURSING SOCIETY; 2003.

9. Sadock BJ. Kaplan \& Sadock's Pocket Handbook of Clinical Psychiatry. Lippincott Williams \& Wilkins Philadelphia, PA; 2010.

10. Maunder RG, Lancee WJ, Rourke S, et al. Factors associated with the psychological impact of severe acute respiratory syndrome on nurses and other hospital workers in Toronto. Psychosom Med. 2004;66 (6):938-942. doi:10.1097/01.psy.0000145673.84698.18

11. Styra R, Hawryluck L, Robinson S, Kasapinovic S, Fones C, Gold WL. Impact on health care workers employed in high-risk areas during the Toronto SARS outbreak. J Psychosom Res. 2008;64(2):177-183. doi:10.1016/j.jpsychores.2007.07.015

12. Bai Y, Lin -C-C, Lin C-Y, Chen J-Y, Chue C-M C-M, Chou P. Survey of stress reactions among health care workers involved with the SARS outbreak. Psychiatric Services. 2004;55(9):1055-1057. doi:10.1176/appi.ps.55.9.1055

13. Tam CINDYWC, Pang EDWINPF, Lam LINDACW, Chiu HELENFK. Severe acute respiratory syndrome (SARS) in Hong Kong in 2003: stress and psychological impact among frontline healthcare workers. Psychol Med. 2004;34(7):1197. doi:10.1017/S0033291704002247

14. Goulia P, Mantas C, Dimitroula D, Mantis D, Hyphantis T. General hospital staff worries, perceived sufficiency of information and associated psychological distress during the A/H1N1 influenza pandemic. BMC Infect Dis. 2010;10(1):322. doi:10.1186/1471-2334-10-322

15. Tan BY, Chew NW, Lee GK, et al. Psychological impact of the COVID-19 pandemic on health care workers in Singapore. Ann Intern Med. 2020;173(4):317-320. doi:10.7326/M20-1083

16. Heath C, Sommerfield A, von Ungern-Sternberg B. Resilience strategies to manage psychological distress among healthcare workers during the COVID-19 pandemic: a narrative review. Anaesthesia. 2020;75(10):1364-1371. doi:10.1111/anae.15180

17. Lai J, Ma S, Wang Y, et al. Factors associated with mental health outcomes among health care workers exposed to coronavirus disease 2019. JAMA Network Open. 2020;3(3):e203976-e. doi:10.1001/ jamanetworkopen.2020.3976

18. Pappa S, Ntella V, Giannakas T, Giannakoulis VG, Papoutsi E, Katsaounou P. Prevalence of depression, anxiety, and insomnia among healthcare workers during the COVID-19 pandemic: A systematic review and meta-analysis. Brain Behav Immun. 2020. 
19. Andrews G, Slade T. Interpreting scores on the Kessler psychological distress scale (K10). Aust N Z J Public Health. 2001;25(6):494- 497. doi:10.1111/j.1467-842X.2001.tb00310.x

20. Sinclair VG, Wallston KA. The development and psychometric evaluation of the Brief Resilient Coping Scale. Assessment. 2004;11 (1):94-101. doi:10.1177/1073191103258144

21. Bøen H, Dalgard OS, Bjertness E. The importance of social support in the associations between psychological distress and somatic health problems and socio-economic factors among older adults living at home: a cross sectional study. BMC Geriatr. 2012;12(1):27. doi:10.1186/1471-2318-12-27

22. Vissoci JRN, Vaca SD, El-Gabri D, et al. Cross-cultural adaptation and psychometric properties of the Kessler Scale of Psychological Distress to a traumatic brain injury population in Swahili and the Tanzanian Setting. Health Qual Life Outcomes. 2018;16(1):147. doi:10.1186/s12955-018-0973-0

23. Ma Y, Rosenheck R, He H. Psychological stress among health care professionals during the 2019 novel coronavirus disease outbreak: cases from online consulting customers. Int Critical Care Nurs. 2020;61:102905. doi:10.1016/j.iccn.2020.102905

24. Gómez-Salgado J, Domínguez-Salas S, Romero-Martín M, OrtegaMoreno M, García-Iglesias JJ, Ruiz-Frutos C. Sense of coherence and psychological distress among healthcare workers during the COVID-19 pandemic in Spain. Sustainability. 2020;12(17):6855. doi:10.3390/su12176855

25. Nie A, Su X, Zhang S, Guan W, Li J. Psychological impact of COVID-19 outbreak on frontline nurses: A cross-sectional survey study. J Clin Nurs. 2020;29(21-22):4217-4226. doi:10.1111/jocn.15454

26. $\mathrm{Hu} \mathrm{Z}$, Chen B. The Status of Psychological Issues Among Frontline Health Workers Confronting the Coronavirus Disease 2019 Pandemic. Fron Public Health. 2020;8:265. doi:10.3389/fpubh.2020.00265

27. Dai Y, Hu G, Xiong H, Qiu H, Yuan X. Psychological impact of the coronavirus disease 2019 (COVID-19) outbreak on healthcare workers in China. MedRxiv. 2020.

28. Holingue C, Badillo-Goicoechea E, Riehm KE, et al. Mental distress during the COVID-19 pandemic among US adults without a pre-existing mental health condition: findings from American trend panel survey. Prev Med. 2020;139:106231. doi:10.1016/j. ypmed.2020.106231
29. Lee AM, Wong JG, McAlonan GM, et al. Stress and psychological distress among SARS survivors 1 year after the outbreak. Canadian J Psychiatry. 2007;52(4):233-240. doi:10.1177/070674370705200405

30. Sher L. The impact of the COVID-19 pandemic on suicide rates. QJM. 2020;113(10):707-712. doi:10.1093/qjmed/hcaa202

31. Panchal N, Kamal R, Orgera K, et al. The implications of COVID-19 for mental health and substance use. Kaiser Family Foundation. 2020.

32. Chodkiewicz J, Talarowska M, Miniszewska J, Nawrocka N, Bilinski P. Alcohol consumption reported during the COVID-19 pandemic: the initial stage. Int $J$ Environ Res Public Health. 2020;17(13):4677. doi:10.3390/ijerph17134677

33. Banerjee A, Pasea L, Harris S, et al. Estimating excess 1-year mortality associated with the COVID-19 pandemic according to underlying conditions and age: a population-based cohort study. Lancet. 2020;395(10238):1715-1725. doi:10.1016/S0140-6736(20) 30854-0

34. Chudasama YV, Gillies CL, Zaccardi F, et al. Impact of COVID-19 on routine care for chronic diseases: A global survey of views from healthcare professionals. Diabetes Metab Syndrome. 2020;14 (5):965-967. doi:10.1016/j.dsx.2020.06.042

35. Shanahan L, Steinhoff A, Bechtiger L. et al. Emotional distress in young adults during the COVID-19 pandemic: evidence of risk and resilience from a longitudinal cohort study. Psychol Med;2020. 1-10. doi:10.1017/S003329172000241X

36. Bauer LL, Seiffer B, Deinhart C, et al. Associations of exercise and social support with mental health during quarantine and social-distancing measures during the COVID-19 pandemic: A cross-sectional survey in Germany. MedRxiv. 2020.

37. Rozanova J, Shenoi S, Zaviryukha I, et al. Social Support is Key to Retention in Care during Covid-19 Pandemic among Older People with HIV and Substance Use Disorders in Ukraine. Subst Use Misuse. 2020;55(11):1902-1904. doi:10.1080/10826084.2020.1791183
Psychology Research and Behavior Management

\section{Publish your work in this journal}

Psychology Research and Behavior Management is an international, peer-reviewed, open access journal focusing on the science of psychology and its application in behavior management to develop improved outcomes in the clinical, educational, sports and business arenas. Specific topics covered in the journal include: Neuroscience, memory and decision making; Behavior modification and management; Clinica applications; Business and sports performance management; Social and developmental studies; Animal studies. The manuscript management system is completely online and includes a very quick and fair peer-review system, which is all easy to use. Visit http://www dovepress.com/testimonials.php to read real quotes from published authors. 